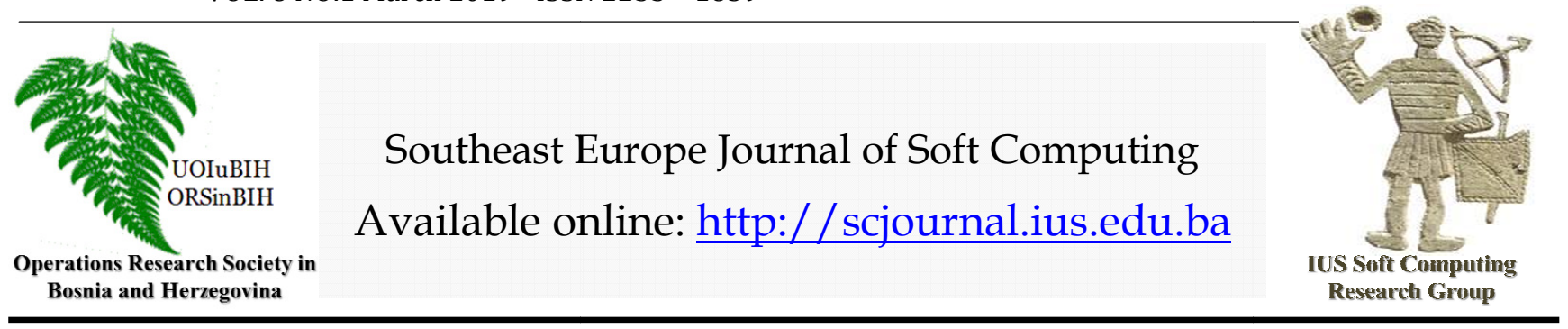

\title{
Investigation Of 16S rRNA Gene And Gene Segments For The Determination Of Probiotics
}

\author{
Amar Ćosié \\ Altijana Hromic Jahjefendic \\ Faculty of Engineering and Natural Sciences, \\ International University of Sarajevo, \\ Hrasnicka Cesta 15, Ilidža 71210 Sarajevo, \\ Bosnia and Herzegovina \\ amar_cosic@outlook.com \\ ahromic@ius.edu.ba
}

\section{Article Info \\ Article history: \\ Article received on 13 February 2019 Received in revised form 25 \\ March 2019}

Keywords:

16S ribosomal RNA; gene segments; diagnosis; bacteria annotation

\begin{abstract}
The 16s-rRNA consists of hypervariable regions (V1 - V9) that demonstrate considerable sequence diversity among different bacteria. Species-specific sequences within a given hypervariable region constitute useful targets for diagnostic assays and other scientific investigations. Usually the size of the gene region is $1500 \mathrm{bp}$, which is large enough to be analyzed using bioinformatic tools and applied for detection. The need to advance the knowledge of the 16s-rRNA gene segments in bacterial strains would allow better understanding and better diagnostic possibilities when dealing with them. This could also be the basis for investigation of pathogenic microorganisms.
\end{abstract}

\section{INTRODUCTION}

Today, DNA-based analysis remains a central method in microbiology, used not only to explore microbial diversity but also as a day-to-day method for bacterial identification. Identification methods are conceptually easier to interpret than molecular phylogenetic analyses and are often preferred when the groups are well understood [1]. Reason for this is the vast amount of phenotypic differences abacteria can show on its surface, which leads to hard identification even with the best laboratories and expertise.
This shows highimportance and need for better and more precise knowledge about the human microbiome.

Bacteria used in this investigation are classified as probiotics which are live bacteria that have positive impact on the digestive tract and the human gut microbiome[4]. Probiotics can be classified into two main genera, Lactobacillus and Bifidobacterium. Probiotics as good bacteria have a vast amount of beneficial impact on the human health, such as increase in the food nutrient value and helping with diseases such as irritable bowel syndrome or lactose intolerance [2]-[5]. 
In this research we investigated 15 different probiotics soys represented in Table 1. These are:Bacillussubtilis, Bifidobacterium bifidum, Bifidobacterium breve, Bifidobacterium infantis, Bifidobacterium longum, Lactobacillus acidophilus, Lactobacillus delbruecki ssp.bulgaricus, Lactobacillus casei,Lactobacillus plantarum, Lactobacillus rhamnosus, Lactobacillus helveticus, Lactobacillus salivarius, Lactococcus lactis ssp. Lactis, Streptococcus thermophilus, Lactobacillus sporogenes.

Table 1: List of bacteria and their nomenclature

\begin{tabular}{|c|c|}
\hline Name of the bacteria & $\begin{array}{l}\text { International Code of } \\
\text { Nomenclature ofBacteria }\end{array}$ \\
\hline Bacillus subtilis & PXN 21 \\
\hline Bifidobacterium bifidum & PXN 23 \\
\hline Bifidobacterium breve & PXN 25 \\
\hline Bifidobacterium infantis & PXN 27 \\
\hline Bifidobacterium longum & PXN 30 \\
\hline Lactobacillus acidophilus & PXN 35 \\
\hline Lactobacillus & PXN 39 \\
\hline
\end{tabular}

\begin{tabular}{|l|l|}
\hline ssp.bulgaricus & \\
\hline Lactobacillus casei & PXN 37 \\
\hline Lactobacillus plantarum & PXN 47/CECT 7315/CECT 7316 \\
\hline Lactobacillus rhamnosus & PXN 54 \\
\hline Lactobacillus helveticus & PXN 45 \\
\hline Lactobacillus salivarius & PXN 57 \\
\hline Lactococcus lactis ssp. lactis & PXN 63 \\
\hline Streptococcus thermophilus & PXN 66 \\
\hline
\end{tabular}

\section{MATERIALS AND METHODS}

Bacteria were provided from multiple suplement pills:Biokult-Oktal Pharm (Croatia), Prolife Capsule-

Zeta Farmaceutici Group (Italy), AB-IMMUNO -AB Biotics (Spain), Feminabiane-PiLeje (France). The growth media MRS both broth and agar were provided by Sigma Aldrich (Germany), while HomofermentativeHeterofermentative differential (HHD) agar was made according to L.C.Mcdonald et. al [6]. Every ingredient for this medium was provided by Sigma Aldrich (Germany). DNA isolation kit (EXTRACTME GENOMIC DNA KIT) and Gel-out kit(EXTRACTMEDNA GEL-OUT KIT) were both acquired from Blirt (Poland). Polymerase Chain Rection primers were acquired from Sigma Aldrich (Germany).

\section{Bacterial Growth}

Probiotics were grown in the incubator (Innova 42 Incubator Shaker Series, Eppendorf North America, USA), at $37^{\circ} \mathrm{C}$ for $24 \mathrm{~h}$. Handling of the bacteria during the inoculation and enumeration was done in sterile environment under the hood (NÜVE I MN 120). These bacteria were grown in two different mediums. DeMan, Rogosa and Sharpe Agar (MRS) as the main medium for Lactobacillus.

HHD agar was mainly used in separation manner. This medium works on the principle of Bromocresol green and the change in the $\mathrm{pH}$ that happens when bacteria is making products. Homofermentative will produce only one product, which is usually lactic acid, and it will show a green color in the medium. Heterofermentative will produce more than one product which does not change the color of the medium and it remains blue. [6]

\section{DNA Isolation}

Bacterial DNA was isolated using the previously mentioned ExtractMe Genomic DNA, which is a fastbp for the primers which were targeting the whole gene, and the $500 \mathrm{bp}$ and $350 \mathrm{bp}$ for the hypervariable regionand reliable way to get high concentrated DNA from bacteria. Expected purity ratio is between 1.7 and 1.9 for the absorbance on $260 / 270 \mathrm{~nm}$ of wavelength. The overall time for the whole protocol is 40-60 minutes with incubation time included.

\section{Polymerase Chain Reaction}

The primers were designed based on previous studies [7][8][9]. Table 2 shows the primer sequence and their reference studies. Amplification target were split into two categories: whole gene where the point was to get as close as possible to $1500 \mathrm{bp}$ which is the length of the 16S-rRNA gene and hypervariable region mainly the V3 and V4 region. PCR conditions were donewiththe thermal cycler (StepOnePlus ${ }^{\mathrm{TM}}$ Real-Time PCR System, Germany). They were carried out as following: predenaturation at $95^{\circ} \mathrm{C}$ for $5 \mathrm{~min}$ followed by 33 cycles each of $95^{\circ} \mathrm{C}$ for $30 \mathrm{sec}, 55^{\circ} \mathrm{C}$ for $45 \mathrm{sec}, 72^{\circ} \mathrm{C}$ for $30 \mathrm{sec}$ and in the end final elongation at $72{ }^{\circ} \mathrm{C}$ for $10 \mathrm{~min}$.

Table 2. Primer sequence and obtained reference studies

\begin{tabular}{|c|c|c|}
\hline Name & Primer Sequence & References \\
\hline $27 \mathrm{~F}$ & 5'-AGAGTTTGATCCTGGCTCAG-3' & [7] \\
\hline $1492 \mathrm{R}$ & 5'-CGGTTACCTTGTTACGACTT-3' & [8] \\
\hline 1492R2 & 5'-CTTGTGCGGGCCCCCGTCAATTC-3' & [7] \\
\hline BA338F & 5'-ACTCC TACGG GAGGC AG-3' & \multirow{3}{*}{ [9] } \\
\hline BA805R & 5'-GACTA CCAGG GTATC TAATC C -3' & \\
\hline BA516F & 5'-TGCCA GCAGC CGCGG TAATA C-3' & \\
\hline
\end{tabular}




\section{RESULTS AND DISCUSSION}

Probiotics such as Lactobacillus and Bifidobacterium are lenient when cultivated. They are easy to grow and can sustain for a long time at the temperatures such as $4^{\circ} \mathrm{C}$. All these properties showed benefits when applied to a differentiation medium such as HHD agar. With this agar it was possible to successfully separate the bacteria based on the number of products they can produce. From here DNA was isolated with the kit that was described in the section Materials and Methods. DNA purity and concentration was high enough to continue to the PCR step in which different DNAs were successfully amplified. The Figure 1 shows clearly the difference in the band size after amplification. Size of those bands were as expected, $1500 \mathrm{bp}$ and 1000 of the gene.

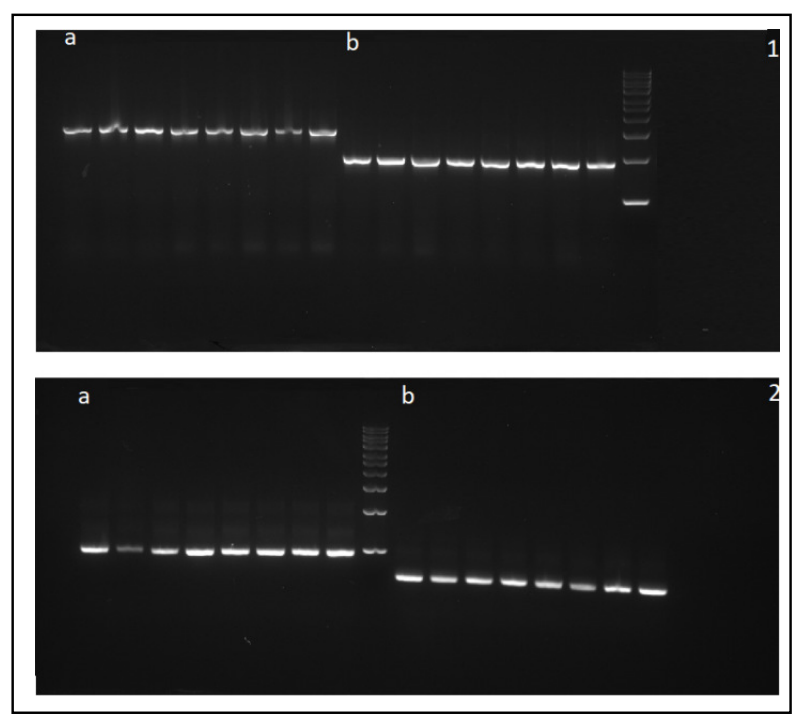

Figure 1: PCR products after amplification. 1a) represents the whole gene segment with the $1500 \mathrm{bp}$ region. $1 \mathrm{~b}$ ) display the $1000 \mathrm{bp}$ amplificon. 2a) represents the $500 \mathrm{bp}$ amplificon while the $2 \mathrm{~b}$ ) depicts the $350 \mathrm{bp}$ region.

\section{CONCLUSION}

The amplified DNAs after purification can be sent to the sequencing. The sequence will provide more information about the bacteria itself and it will prove that using the HHD medium and universal primers represents a reliable source when it comes to identification of bacteria by combining the PCR and bioinformatic analysis.

\section{REFERENCES}

[1] C. P. Kolbert and D. H. Persing, "Ribosomal DNA sequencing as a tool for identification of bacterial pathogens," Curr. Opin. Microbiol., vol. 2, no. 3, pp. 299-305, Jun.1999.

[2] G. Barbara, C. Cremon, and F. Azpiroz, "Probiotics in irritable bowel syndrome: Where are we?," Neurogastroenterol. Motil. Off. J. Eur. Gastrointest. Motil. Soc., vol. 30, no. 12, p. e13513, Dec. 2018.

[3] S. Grover, H. M. Rashmi, A. K. Srivastava, and V.K. Batish, "Probiotics for human health newinnovations and emerging trends," Gut Pathog., vol. 4, p. 15, Nov. 2012.

[4] P. Markowiak and K. Śliżewska, "Effects of Probiotics, Prebiotics, and Synbiotics on Human Health," Nutrients, vol. 9, no. 9, Sep. 2017.M. Majeed et al., "Bacillus coagulans MTCC 5856 supplementation in the management ofdiarrhea predominant Irritable Bowel Syndrome: a double blind randomized placebo controlled pilot clinical study," Nutr. J., vol. 15, Feb. 2016.

[5] L. C. McDonald, R. F. McFeeters, M. A. Daeschel, and H. P. Fleming, "A Differential Medium for the Enumeration of Homofermentative and Heterofermentative Lactic Acid Bacteria," Appl. Environ. Microbiol., vol. 53, no. 6, pp. 1382-1384, Jun. 1987.

[6] S. Srivastava et al., "Identification of regulatory elements in 16S rRNA gene of Acinetobacter species isolated from water sample," Bioinformation, vol. 3, no. 4, pp. 173-176, Dec. 2008.

[7] S. Xiang, T. Yao, L. An, B. Xu, and J. Wang, "16S rRNA Sequences and Differences in Bacteria Isolated from the Muztag Ata Glacier at Increasing Depths," Appl. Environ. Microbiol., vol. 71, no. 8, pp. 46194627, Aug. 2005.

[8] Y. Yu, C. Lee, J. Kim, and S. Hwang, "Groupspecific primer and probe sets to detect methanogenic communities using quantitative real-time polymerase chain reaction," Biotechnol. Bioeng., vol. 89, no. 6, pp. 670-679, 2005. 